\title{
Sense of coherence as a stress moderator in students
}

\begin{abstract}
Overview: A Mood disorder, especially anxiety and depression is increasingly present between undergraduate health students. Stress and its consequences are dependent on how the person coping with stressors. The sense of coherence(SOC) is a characteristic of personality developed in the salutogenic model (Antonovsky -1923-1996), which suggests reducing the effects of stress by modifying the perception of the stressful situation, and improving coping strategies.
\end{abstract}

Objective: This study aims to analyze the Sense of Coherence (SOC) as a moderator of the Perceived Stress (PS) between nursing and gerontology students in the first period of their courses.

Method: An exploratory study with a quantitative approach was carried out with 38 nursing and gerontology students at a public university in a country town from São Paulo, Brazil before the period of assessment. Reliability instruments was performed by Alpha Cronbach test (SOC Scale, $\alpha=0.856$ and PSS $\alpha=0.848$ ). Results: SOC and PSS Pearson test showed a negative correlation with high association $(\mathrm{r}=-0.8507+95.55$, $\mathrm{R} 2=0.454)$.

Conclusion: We conclude that nursing and gerontology students are under stress, even before starting their specific professional content. The SOC can moderate the perceived stress among students in this period.

Keywords: sense of coherence, stress, nursing, students, gerontology
Volume 5 Issue 6 - 2018

Stefanie Leda, Eliane da Silva Grazziano

Nursing Department, Federal University of São Carlos/SP, Brazil

Correspondence: Eliane da Silva Grazziano, Nursing Department, Federal University of São Carlos, Federal University of São Carlos, Highway Washington Luís, Km 235-PO Box 676. São Carlos, SP, Brazil, Tel 55-16-335|8334, Email eligraziano@gmail.com

Received: June 03, 2018 | Published: November 16, 2018

\section{Introduction}

Professional training in the healthcare courses aims at the care of people with physical and emotional fragilities. The healthcare students, especially in the first year of their courses need a period of adaptation to deal with stressful situations, such as dealing with pain, emotional and psychological suffering, loss and mourning, with bodily intimacy and frustration. ${ }^{1}$ Researches carried out with nursing undergraduates verified the presence of stress, burnout and depression among them, and indicated as factors generating high stress, improper time management, high demand for theoretical and practical classes, and traditional and non-innovative teaching methods, according to the semester which course. ${ }^{1,2}$ The final periods of health courses lead to greater stress due to internships and future expectations: to get a job or complementing training with specialization or improvement courses? However, a prior question must be answered: how the stress and anxiety of younger healthcare students could be reduced? Or, how to promote stress coping resources for them? With the advent of positive psychology, in the last decades, researchers have developed studies to understand the influence of personality traits that are protective against stress and mood disorders. The Sense of Coherence(SOC) is a construct developed in the salutogenic model, proposed by Antonovsky, ${ }^{3}$ which suggests a holistic view of the individual centered on the generation of health through the regulation of emotional tension, besides positively influencing the decisions which affect quality of life: adoption of healthy habits and the choice to remain confident in the face of a stressful situation; persons with high SOC present higher disposition to face with the daily stressors. ${ }^{3,4}$ The SOC presents 3 components: the (a)understanding, that refers to the meaning that the person attribute to the stressful situation; (b)management, refers to the individual perception that his or she is capable to face and overcome the stressful situation, and the (c)meaning that is the feeling that life makes sense and that changes are welcome. ${ }^{5}$ Although Antonovsky ${ }^{3}$ initially stated that SOC develops in the first 3 decades of life, research has shown that this personality trait can be "trained" and strengthened throughout it. ${ }^{4}$ SOC contributes to reduce the effects of stress by modifying the perception of the situation, reducing the negative impact of stressors by cognitive assessment and coping strategies. These personality traits are highly desirable for health maintenance. ${ }^{6}$ Assuming that the students of the first semester begin the course with a higher perception of stress due to the changes that occurred in this period this study aimed to identify the perception of the general stress of this population and the presence of a sense of coherence as a protective factor to stressful situations.

\section{Methods}

An exploratory and cross-sectional study with a quantitative approach carried out between 2015-2016, with 11 nursing students (36.67\% of the total number of students in the first semester), and 27 gerontology students $(67.5 \%$ of the total number of students in the first semester) at a federal public university of the state of São Paulo, Brazil. The total sample was 38 students. Research was approved by the Committee on Ethics and Research, CAAE No. 23792313.6.0000.5504. The Sense of Coherence Scale (SOC) ${ }^{3}$ and the Perceived Stress Scale (PSS) (Cohen, Kamark e Mermelstein, 1983) were applied in its Brazilian Portuguese versions. ${ }^{5,7}$ Data were analyzed by the software program Statistical Package for Social Science (SPSS) version 17.0 and the Statistical Analysis System (SAS). We applied the Cronbach Alpha Coefficient (CAC) to test the scales reliability, and Pearson $\mathrm{R}$ test for correlations. 


\section{Results}

The CAC for SOC Scale was 0.856 , and PSS 0.848, attesting the reliability of the instruments. Thirty-eight students participated, $27(71.05 \%)$ of the Gerontology Course and 11 (28.94\%) of the Nursing Course. The sample was of female students (34-89.47\%), with mean age was $21.39(\mathrm{sd}=6.35$, Min=17, Max=44) years, living with the family $(24-63.16 \%)$, single (33-86.84\%), without previous professional experience (35-92.1\%). SOC mean score was 54.90(sd=11.74; Min-Max=32.76-74.14); PSS mean score was 27.86 $(\mathrm{sd}=8.15$; Min-Max=12.00-44.00) (Figure 1).

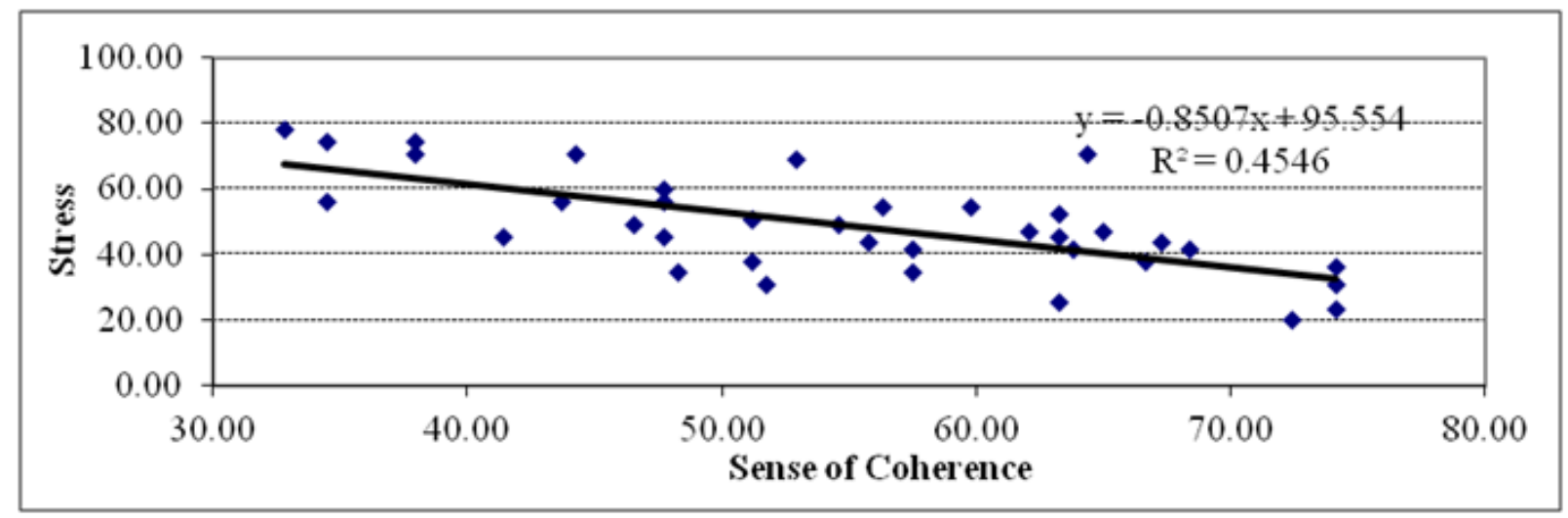

Figure I The Pearson test between SOC and PSS presented a negative correlation with high association $(r=0.8507 ; p<0.00 I)$.

\section{Discussion}

Although the sample of the present study was small, the findings are similar to others researches with students of the last semesters of health courses. ${ }^{8}$ The mean PSS score indicated a medium stress perception for the sample, considering that it is first year students and they are beginners in training for their specific courses. This finding contradicts the results of studies that attribute the inherent characteristics of health course training as factors that increase student stress. ${ }^{1,2,8}$ In a survey carried out by the National Forum of Pro-Rectors of Community and Student Affairs (Fonaprace) commissioned by the National Association of Directors of Federal Institutions of Higher Education ${ }^{9}$ with 19,691 students of higher education at federal universities in Brazil in 2010-2011, revealed that $39.95 \%$ of the students had some emotional difficulty during the last year of the course, and $39.5 \%$ were affected by emotional difficulties at the beginning of the course. ${ }^{9}$ In addition, students' academic performance was affected in different proportions due to emotional difficulties, such as anxiety (70\%), sleep disorders (44\%), feeling of despair and hopelessness (36\%), feeling of inattention and mental confusion $(31 \%)$, excessive shyness $(25 \%)$, depression $(22 \%)$, fear or panic (14\%) and eating problems $(12 \%) .^{9}$ The present study found a negative and strong correlation among PSS and SOC, indicating that SOC can moderate the perceived stress for the students. An intervention study performed with a group of 43 first-year college students found that SOC and self-efficacy are significantly related to the increase in hope levels and average grade in the course.${ }^{10}$ Another study also examined the relationship between SOC and academic performance, based on the analysis of the number of absences of 2824 Japanese university students, in which it was concluded that SOC can help prevent health problems, and students with a strong SOC are less likely to decrease their academic performance when they are ill. ${ }^{11}$ Based on these findings, it is possible to infer that interventions aimed at increasing the sense of coherence involving first-year students may be strategies to help them from the deleterious effects of stress, as well as contribute to the adoption of a salutogenic attitude towards life.

\section{Conclusion}

The stress of healthcare students should be monitored since beginning and during the course, and the cases that indicate possible disorders should be referred to medical and psychology professionals for follow-up. More investigations there are necessary to understand the stress occurrence among healthcare students and to propose interventions to help them to cope with it. The SOC can moderate the perceived stress among students in this period.

\section{Acknowledgements}

None.

\section{Conflict of interest}

Authors declare no conflicts of interest.

\section{References}

1. Costa ALS, Polak C. Construção e validação de instrumento para avaliação de estresse em estudantes de enfermagem (AEEE). Rev Esc Enferm USP. 2009;43:1017-1026.

2. Freitas EO. Estresse, coping, burnout, sintomas depressivos e hardiness entre discentes de enfermagem. Rio Grande do Sul, Santa Maria: Universidade Federal de Santa Maria. 2012. 141 p.

3. Antonovsky A. The structure and properties of the sense of coherence scale. Soc Sci Med. 1993;36(6):725-733.

4. Eriksson M, Lindströn, B. Antonovsky's sense of coherence scale and its relation with quality of life: a systematic review. J Epidemiol Communitty Health. 2007;61(11):938-944.

5. Dantas RAS. Adaptação cultural e validação do Questionário de Senso de Coerência de Antonovsky em uma amostra de pacientes cardíacos brasileiros. Ribeirão Preto: Escola de Enfermagem da Universidade de São Paulo. 2007:1-26.

6. Torsheim T, Aaroe LE, Wold B. Sense of coherence and school-related 
stress as predictors of subjective health complaints in early adolescence: interactive, indirect or direct relationships. Social Science \& Medicine. 2001;53(5):603-614.

7. Reis RS, Hino AAF, Anez CRR. Perceived stress scale: reliability and validity study in Brazil. J Health Psychol. 2010;15(1):107-114.

8. Brandtner M, Bardagi M. Sintomatologia de Depressão e Ansiedade em Estudantes de uma Universidade Privada do Rio Grande do Sul. Gerais: Revista Interinstitucional de Psicologia. 2009;2(2):81-91.
9. Andifes. Fórum Nacional de Pró-Reitores de Assuntos Comunitários e Estudantis. 2011

10. Davidson OB, Feldman DB, Margalit M. A focused intervention for 1st year college students: promoting hope, sense of coherence, and selfefficacy. J Psychol. 2012;146(3):333-352.

11. Okumura R. Stress coping ability in nursing students: studies on the influence factor of Sense of Coherence (SOC). Jpn Hosp. 2012;31:71-79. 